\title{
JUEGO DE TRONOS: \\ DISPUTAS DE PODER EN LA COMEDIA DE CALDERÓN ${ }^{1}$
}

\author{
Adrián J. Sáez \\ Université de Neuchâtel \\ Institut de Langues et Littératures Hispaniques \\ Espace Louis-Agassiz 1 \\ CH-2000 Neuchâtel \\ adrian.saez@unine.ch
}

«también la guerra es juego»

(Argenis y Poliarco, v. 468)

Quien espere algo más que un guiño a la saga "Game of Thrones» - en su versión novelesca o televisiva - ha de quedar forzosamente decepcionado, toda vez que solo pretendo centrarme en uno de los conflictos mayores del teatro de Calderón: las luchas por el poder.Y es que si la dramaturgia calderoniana está sembrada de reyes lascivos, príncipes imperfectos y demás poderosos de relumbrón, es de ley reconocer que la disputa por el gobierno - del reino a un ducado cualquiera- posee un lugar de honor entre tantas discusiones variopintas, quizá (pero solo quizá) porque era un asunto de rabiosa actualidad tanto en Europa

\footnotetext{
${ }^{1}$ Este trabajo se enmarca en el proyecto SILEM: Sujeto e institución literaria en la Edad Moderna (FFI2014-54367-C2-1-R del MINECO) coordinado por Pedro Ruiz Pérez (Universidad de Córdoba). Mi querida Ana Zúñiga Lacruz (Universidad de Navarra), que de reinas sabe mucho, me ha echado una mano con amables comentarios que agradezco sinceramente.
} 
como en la Corona hispánica, que acabaría por llevar a un punto muerto a los Austrias y al cambio de dinastía en España.

\section{LA COMEDIA DEL PODER}

Es claro que en la comedia áurea casi todo se puede tomar en serio o ponerse en solfa según los géneros, el contexto y las convenciones, pero también es verdad que hay una serie de elementos que son más caros a Heráclito que a Demócrito ${ }^{2}$. Más en detalle, se trata generalmente de ideas y conceptos relacionados con el mundo de la política y el poder: si la simulación puede ser tanto una traza ingeniosa y divertida como un ardid de prudencia política, motivos como el tiranicidio, paradigmas como la embajada y temas como la privanza — entre otros- se prestan preferentemente a un tratamiento serio, por mucho que aparezcan en comedias cómicas ${ }^{3}$.

Estos y otros conceptos e ideas de ars gubernandi se dan cita en el teatro calderoniano conformando un camino válido para ver elementos serios en la comedia cómica sin columpiarse hacia exégesis políticas, trágicas y otros esdrújulos del mismo jaez $z^{4}$. Si bien la tentación de la historia pica con ganas, entiendo que todo posible recuerdo está sometido a un proceso de transformación ficticia que hace más oportuno valerse de conceptos e ideas políticas antes que buscar reflejos directos sin ton ni son ${ }^{5}$.

Entre todas las cuestiones al alcance brillan con fuerza los conflictos sucesorios, que arrastran consigo una serie de claves políticas de máxima actualidad, como los problemas de la primogenitura y la ley sálica, el gobierno de la mujer, los derechos de gobierno frente a los intentos de usurpación, los matrimonios de conveniencia, etc.

${ }^{2}$ Arellano, 2011, pp. 143-194; y Sáez, 2012a, examinan diferentes aspectos de la autoridad y el poder en Calderón.

${ }^{3}$ Sobre algunas de estas cuestiones, ver Sáez, 2012b, 2014, 2015 y en prensa.

${ }^{4}$ Para el pensamiento político de Calderón, ver Strosetzki, 2008.Y contra las lecturas tragedizantes, ver Arellano, 1999.

${ }^{5}$ Ver Hildner, que considera que en algunos casos Calderón intenta «realzar las comedias fundamentalmente cómicas mediante la inserción de la vida pública/política» (2008, p. 1). 


\section{INTRIGAS CORTESANAS Y DISPUTAS DE PODER}

Para hacer justicia a lo que llevo diciendo, voy a comentar las peleas por la corona en algunas comedias palatinas (Afectos de odio y amor, Cómo se comunican dos estrellas contrarias) y otras caballerescas (Auristela y Lisidante, El castillo de Lindabridis, Hado y divisa de Leonido y Marfisa, de tono algo menos risueño) que hacen las veces de pareja ligera — si no siempre cómica- de las luchas de poder en La cisma de Ingalaterra, En la vida todo es verdad y todo mentira, La gran Cenobia, La hija del aire, Saber del mal $y$ del bien, La vida es sueño y otros dramas serios cuando no trágicos ${ }^{6}$. Además, si se abre un poco la mano en la concepción del conflicto de poder, el corpus crece con la adición de La selva confusa, Lances de amor $y$ fortuna, Mujer, llora y vencerás, Para vencer amor, querer vencerle y algún otro texto en los que generalmente un ducado está sobre el tablero en una disputa que se concibe en términos similares ${ }^{7}$.

Para poner un poco de orden, se pueden deslindar tres modelos principales de conflicto:

1) Los litigios por el gobierno, que abarcan desde enfrentamientos constantes (las reinas Arminda y Mitilene por Trinacria en Hado y divisa de Leonido y Marfisa, Juana y Andrés en El monstruo de la fortuna, los hermanos en El castillo de Lindabridis) y un gobierno compartido que roza la ruptura (Auristela y Clariana en Auristela y Lisidante).

2) Las luchas de poder y las intrigas palaciegas, que comprende las tensiones religiosas de Afectos de odio y amor (más su envés autosacramental de La protestación de la fe), el descarte de Elvira de Toro por su condición de mujer en Cómo se comunican dos estrellas contrarias, el tiranicidio y las críticas al gobierno femenino en La gran Cenobia, el combate abierto entre Anajarte y el rey en La fiera, el rayo y la piedra, el ansia de

\footnotetext{
${ }^{6}$ Se puede añadir la comedia en colaboración El monstruo de la fortuna y una mención al desastre de Alcazarquivir en El príncipe constante: «en la margen arenosa / del África ha de tener / la portuguesa corona / sepulcro infeliz» (vv. 374-377). Sobre la vindicación calderoniana de Cómo se comunican dos estrellas contrarias, ver Vega GarcíaLuengos, 2005.

${ }^{7}$ Así se nota en dos pasajes de Lances de amor y fortuna: «De tu estado — si es que es tuyo- / Estela saldrá al instante / para ser señora en otro, / mientras vuelve a coronarse /en este» (p. 674); «Todo se ofrece a esos pies, / triunfad, y vuestra persona, / digna de mayor corona, / la imperial ceñida vea, / por que todo el mundo sea / de quien es hoy Barcelona». Sobre el modelo de la comedia palatina, ver especialmente Vitse, 1990 (que prefiere el marbete de «comedia palaciega»); y Zugasti, 2003.
} 
poder y la usurpación — con disimulación incluida — en La hija del aire, el enredo amoroso y político de Mujer, llora y vencerás, y las conspiraciones cortesanas contra Alfonso VII en Saber del mal y del bien.

3) El problema sucesorio, que resulta esencial en En la vida todo es verdad y todo mentira y se deja abierto en el cierre de La cisma de Ingalaterra, además de la preocupación por la ley sálica presente en Afectos de odio $y$ amor y La fiera, el rayo y la piedra y algunas comedias más.

De todo este catálogo, merece la pena examinar con algo más de detalle el manojo de comedias palatinas que tratan una y otra vez el tema de la sucesión: para empezar, está la primerísima comedia de Calderón, La selva confusa (1622-1623, impreso en dos colectáneas de 1632-1633) y luego Lances de amor y fortuna (1624-1625, aparecida en la Primera parte, Madrid, María de Quiñones, 1636), Para vencer amor, querer vencerle (1630-1633, representada en 1650 y presente en la Séptima parte de escogidas, Madrid, Domingo García Morrás, 1654), Afectos de odio y amor (1644-1659, Tercera parte de comedias, Madrid, Domingo García Morrás, 1664) y Mujer, llora y vencerás (1659-1660, compuesta para el Carnaval de 1660 y publicada en la Verdadera quinta parte, Madrid, Francisco Sanz, 1682, a cura de Vera Tassis) ${ }^{8}$. Primas hermanas de estas son tres comedias caballerescas que lidian con el mismo asunto: Auristela y Lisidante (h. 1663, Séptima parte, Madrid, Francisco Sanz, 1683, de nuevo mimada por Vera Tassis), El castillo de Lindabridis (1661-1663, Parte novena, Madrid, Francisco Sanz, 1691, editada porVera Tassis) y la fiesta real Hado y divisa de Leonido y Marfisa (1680, Verdadera quinta parte de comedias), la última obra calderoniana, más el temprano botón de Argenis y Poliarco (16271629, Segunda parte, Madrid, María de Quiñones, 1637), que ofrece una variante del conflicto.

Con este racimo de textos se abarca la producción de Calderón desde sus inicios, lo que refleja que el juego por el poder es un tema que interesa constantemente al poeta, que lo modula a su antojo en una serie de comedias pensadas para el ámbito cortesano en las que quizá se puedan encontrar consejos, lecciones y situaciones claramente conectadas con el arte de gobierno de la época ${ }^{9}$. En este orden de cosas, se aprecia una suerte de distribución por géneros, ya que — salvo el conflicto internacional de Afectos de odio y amor-, las comedias palatinas prefieren

\footnotetext{
8 Todas las fechas proceden de las ediciones manejadas o de Cruickshank, 2011.

${ }^{9}$ Ver los interesantes comentarios de Coenen, 2011.
} 
delinear el conflicto por condados y ducados mientras los dramas caballerescos se centran decididamente en las peleas por el trono stricto sensu y con menos toques cómicos, por cierto.

Acaso por esta dimensión didáctica la comicidad es moderada, por lo que Zugasti entiende que las comedias palatinas en cuestión son eminentemente serias, a la vez que tampoco los dramas caballerescos constituyen una fiesta de la risa, de modo parejo a las piezas mitológicas que tanto gustaban a los reyes ${ }^{10}$. Este pequeño exilio de la comicidad, que sobrevive esencialmente en las chanzas de los graciosos, se aprecia perfectamente en el caso de Mujer, llora y vencerás, que forma parte del ciclo de comedias grises con los que Calderón experimenta en su alejamiento progresivo del humor en torno a la década de $1640^{11}$.

\section{Conflictos de palacio}

En el principio de todo está la cuestión de la sucesión, que arranca con las circunstancias del nacimiento de los hermanos y todavía antes con la relación amorosa de los padres. La selva confusa se abre con un lance muy violento que ya pone el dedo en la llaga: el príncipe Filipo aprovecha una expedición de caza para tejer una emboscada a su hermano Fadrique Esforcia y asegurarse el ducado de Milán. En su parlamento justifica la traición porque, pese a que posee mayores derechos, recela que el favor del pueblo pueda compensar la distancia que va de un hijo legítimo a otro natural (vv. 100-189), y de nada vale la disculpa de Fadrique, que descarta toda ambición:

Como hermano te he querido, y si hoy el duque muriera, hoy jurara yo el primero en tus manos la obediencia. (vv. 230-233)

Frente a la tónica habitual, el conflicto se desata previamente al vacío de poder y tan solo por unas sospechas imaginadas que retratan desde el inicio al príncipe como un cortesano amigo de las peores intrigas y a

${ }^{10}$ Zugasti, 2003, pp. 167-168, entiende que la comedia palatina es seria cuando predomina la cuestión política sobre el tema amoroso.

${ }^{11}$ Sobre estas comedias sombrías, que principia con No hay cosa como callar (1638) y se cierra justamente con Mujer, llora y vencerás, ver Cruickshank, 2011, pp. 421-422. 
Fadrique como un personaje modélico, justo la distancia que va de «la heredada / a la adquirida nobleza» (vv. 296-297).

Por mucho que el ataque se quiere compensar con una oferta de destierro (vv. 258-274), Fadrique prefiere huir dando inicio al tapiz de enredos que definen la acción de la comedia, que finalmente se cierra con una decisión salomónica que contenta a todos:

Filipo de Milán es heredero, y si a Jacinta adora, case con ella, y con Fadrique Flora, que es la que a Mantua hereda. (vv. 3622-3625)

A su vez, en Lances de amor y fortuna la disputa se centra en la legitimidad de la concepción de los hijos: aunque teóricamente por edad el ducado le tocaría en suerte a Aurora, Estela defiende sus derechos porque fue concebida dentro del matrimonio, mientras que su hermana es fruto de un casamiento secreto que luego tuvo que rubricarse oficialmente:

\section{hay antigüedad que mande que, si hay legítimo hijo, este herede y, cuando falte, el bastardo y natural. (p. 669)}

De poco sirve que Aurora argumente su legitimidad con razones jurídico-teológicas («es bastante / matrimonio para el cielo / la unión de dos voluntades», pp. 671-672) y ofrezca un gobierno conjunto («mandemos en él iguales; / tuyo será, siendo mío», p. 673), pues Estela prefiere la guerra en parte porque se mueve por una gran ambición que le lleva a desear «sujetar [...] / del mundo las cuatro partes» (p. 671).

Pareja es la situación en Para vencer amor, querer vencerle, comedia en la que se enfrentan amor y política desde el inicio, porque el matrimonio entre don César Colona y su prima Margarita responde solamente a las leyes de la sucesión:

El gran duque de Ferrara, tío de los dos, que yace en mejor imperio, adonde son eternas las edades, sin hijos murió, de suerte 


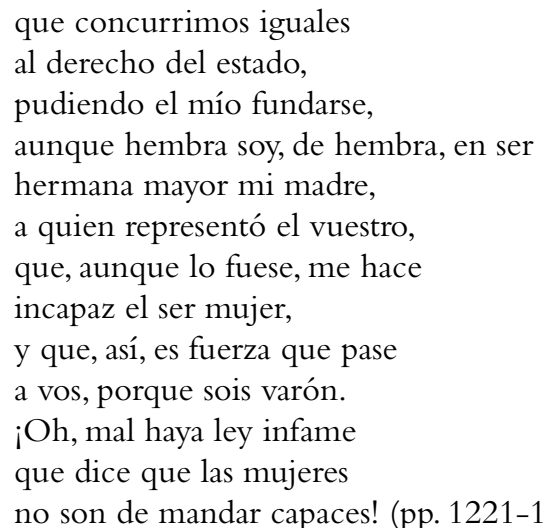

que concurrimos iguales

al derecho del estado,

pudiendo el mío fundarse,

aunque hembra soy, de hembra, en ser

hermana mayor mi madre,

a quien representó el vuestro,

que, aunque lo fuese, me hace

incapaz el ser mujer,

a vos, porque sois varón.

¡Oh, mal haya ley infame

no son de mandar capaces! (pp. 1221-1222)

Frente a esta situación, Margarita acepta un matrimonio forzado, pero la revelación secreta de su rechazo a César en parte por su común parentesco (pp. 1223-1224) —un claro remite a los casamientos entre familiares en las cortes europeas - hace que este salga a toda prisa de Ferrara para sorpresa general de todos, que no logran comprender la renuncia de César a dama y ducado (p. 1258).

La renuncia absoluta de César a su amor y a sus derechos sucesorios se plasma en una desesperada partida a la guerra y en reiteradas proclamas a favor de su prima Margarita, que sin embargo se van a quedar en nada porque la confirmación del título corresponde al emperador Federico III:

$$
\begin{aligned}
& \text { porque, siendo aqueste estado } \\
& \text { desde sus antigüedades } \\
& \text { feudatario del imperio, } \\
& \text { es jurado vasallaje } \\
& \text { hasta que a leer la sentencia } \\
& \text { él mesmo de no gozalle } \\
& \text { ninguno, haciendo en sus manos } \\
& \text { pleitesías y homenajes. (p. 1222) }
\end{aligned}
$$

La huida a la carrera acaba por ser la solución idónea, porque el aventurero César se gana el favor del emperador y este acaba por reconocerle como gran duque de Ferrara por dos razones claramente políticas: es el candidato ideal para mantener a su favor un estado estratégicamente decisivo tras la contienda contra los esguízaros («de Italia / y Alemania confinantes", p. 1229), a la vez que su matrimonio con Matilde, baronesa 
de Momblanc, le permite recompensar a un aliado fundamental en la guerra que vive exiliada de su tierra (pp. 1274 y 1309). Por tanto, Para vencer amor, querer vencerle añade a la cuestión sucesoria el dilema entre el amor por interés (representado por Margarita) y las conveniencias de la razón de estado, en un bivium resulto gracias a la intervención de una autoridad superior (el emperador).

En Afectos de odio y amor se une la sucesión del ducado de Rusia con los afanes bélicos de Sigismundo de Gocia y Cristerna de Suevia, que ponen en guerra a todo el norte con la colaboración de Federico de Albania. Junto a esta lucha internacional entre el amor y el poder, en el centro de la comedia se encuentra el gobierno de la mujer, pues Cristerna es heredera del rey Adolfo por la abolición de la ley sálica («en reino donde / $\tan$ poco ha que fue depuesta / la salia ley, que dejaba / desheredadas las hembras», p. 483), al punto que ordena una nueva disposición contra esta costumbre "con las mujeres tirana» (p. 490).Y, a pesar de que al final queda en nada, una chanza del gracioso resulta bien significativa desde la perspectiva de la actuación de la reina Cristerna y Auristela, hermana de Casimiro de Rusia: «[...] ¿qué fuera que se viese / acabar una comedia / casándose dos mujeres?» (p. 587).

En este grupo de comedias se añade las más de las veces otra dimensión del conflicto, sea más social (interna) o de política internacional (externa): así, en Lances de amor y fortuna se complica la cosa con la lucha entre los bandos catalanes comandados por el duque de Ruisellón y el conde de Urgel, mientras que cada uno de los hermanos en Mujer, llora y vencerás recibe el apoyo de estamentos enfrentados (la nobleza para el uno, el pueblo para el otro, pp. 392-393); en cambio, el posible casamiento de Fadrique con Flora en La selva confusa toca de lejos una posible unión entre los ducados de Milán y Mantua, así como la guerra dinástica entre Gocia, Suevia y Rusia recorre de principio a fin Afectos de odio y amor.

Todavía más complejo es el panorama en Mujer, llora y vencerás, que es un caso paradigmático del abanico de cuestiones en liza dentro de las disputas dramáticas por el poder ${ }^{12}$. El conflicto por la sucesión al archiducado de Turingia tras la muerte del landgrave de Hassia (uno de los territorios del Sacro Imperio Romano Germánico, modernamente

12 Soons, 1989, p. 640, entiende que en este texto puede haber una «clave en la política dinástica europea de la época», mientras Rull, 2002, p. 394, considera que es una comedia "sólo bélica en apariencia». 
Hesse) se lo disputan a tres bandas madama Inés (la hija), Enrique y Federico (los sobrinos), con dos dificultades capitales: si de un lado el título corresponde a uno de los dos hermanos varones frente a la defensa numantina de Inés, de otro se suma la condición de gemelos de Enrique y Federico ${ }^{13}$. Al poco de comenzar se explica que deriva del riesgo del parto:

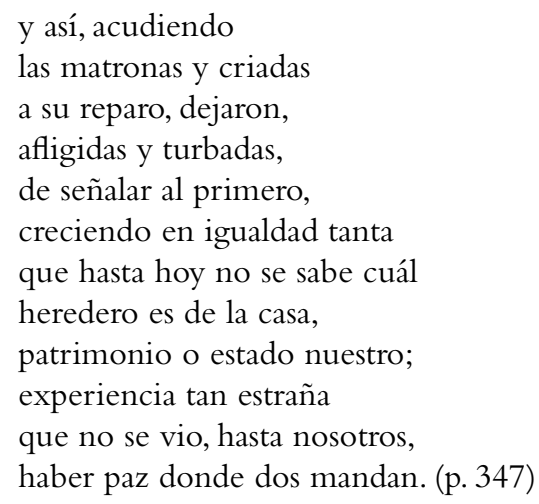

Esta discusión sobre la primogenitura, que se repite con la variante de gobierno a dúo en Auristela y Lisidante, se redondea con el carácter de mujer varonil de madama Inés, nueva Semíramis (p. 340) que defiende sus derechos con uñas y dientes, al tiempo que se niega al casamiento por principio. Este rechazo es el catalizador del conflicto y está a punto de arriesgar su reino, ya que los pretendientes se juegan el todo por el todo mediante las armas, pero Inés solo accede a contraer matrimonio a regañadientes cuando llegan rumores de «callado motín» (p. 349):

\section{Si Federico}

y Enrique, en quien hoy la clara sangre ilustre de landgrave ilustres pechos esmalta, tienen al Hassia y Turingia la justicia hereditaria que les dio el cielo, ¿por qué ha de padecer la patria hostilidades, pudiendo tan fácilmente enmendarlas?

${ }^{13}$ Ver Dahlgren, 1988, que relaciona este esquema con la commedia dell'arte. 
Pues habiendo de casar con otro señor de Madama —quizá estraño—, ¿cuánto es mejor si con uno casa de los dos, que ambos derechos en un patrimonio caigan y a nosotros nos gobierne la siempre ilustre prosapia de nuestro duque? Conque su estado, que también se halla hoy indeciso, tendrá -quedando el uno en su casa, pasando el otro a la nuestra-, señor, que en buena alianza se conserve con nosotros, escusando las desgracias que tray la guerra tras sí de hurtos, muertes, penas y ansias. (p. 350)

De modo parejo a la decisión de Serafina en Las manos blancas no ofenden, Inés somete su voluntad por el bien común, con lo que ejerce como buena gobernante al dar preferencia a su deber sobre sus deseos, de acuerdo con la metáfora de los dos cuerpos del rey ${ }^{14}$. En un baile de idas y vueltas en torno a la decisión final (los amantes pasan la pelota a Inés, esta al parlamento y de nuevo vuelta a la dama) llega una solución tan discreta como verdadera con una caída fingida durante un baile que le permite tanto satisfacer su amor (dar la mano a Enrique, su preferido) como cumplir con su obligación y guardar el decoro, encubriendo sus deseos como elección del destino.

La violenta reacción de Federico, que apresa a su hermano y pone sitio a la ciudad sin detenerse hasta que las lágrimas de Inés lo calman - un poco a la manera de la historia de Coriolano que Calderón retoma en Las armas de la hermosura- pone sobre la mesa un nuevo tema propio de la teoría política de los siglos XVI y Xvir: la quaestio de iure belli, en la que se debatía sobre los motivos válidos para la guerra ofensiva.Ya lo avisan Adolfo y Celio (pp. 439-441), pero el parlamento de madama Inés es cristalino:

${ }^{14}$ Ver todos los detalles en Kantorowicz, 1985. 


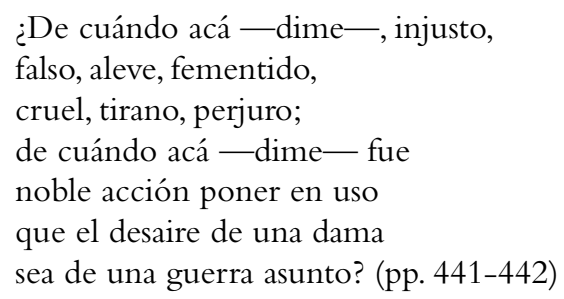

Si algunos tratadistas - como Vitoria - admitían una serie de motivos oportunos para la guerra justa (la injuria grave, la recuperación de lo arrebatado, la lucha contra la opresión y el castigo de los enemigos), nunca aparece el desengaño amoroso ni otras pasiones como causa suficiente, con lo que se hace manifiesto el desgobierno de Federico. Por si fuera poco, al yerro político se suma la nocturnidad y la alevosía que le reprocha madama Inés (p. 442), por tratar de tomar escondidamente lo que no ha podido conseguir cara a cara.

Conjuntamente, se da una gran transformación en los personajes que integran el triángulo amoroso de la comedia, empezando por los gemelos: de ser el partido ideal, Federico se precipita hasta ser un tirano sin control; al revés, Enrique acaba por ser un modelo de gobernante. A su vez, Inés deja de ser una mujer esquiva que odia al hombre y al matrimonio para convertirse en un exemplum político que logra vencerse a sí mismo para perfeccionar su perfil personal y político: paradójicamente, la manifestación de su carácter femenino que podría ser un símbolo de derrota «se convierte en signo de victoria para su pueblo y para ella misma» ${ }^{15}$.

Si puede resonar algún eco histórico o legendario (tal vez el conflicto sucesorio de Hasia en Mujer, llora y vencerás y desde luego los avatares de Cristina de Suecia en Afectos de odio y amor), no es para nada necesario que las fábulas sigan modelo alguno, toda vez que muchos lances (enfrentamiento fraterno, mujer varonil, victoria misericordiosa, etc.) son típicos de la «marca Calderón» y el enfrentamiento por el poder constituye tanto un tema de gran fuerza dramática como una cantera excepcional para abordar un amplio ramillete de cuestiones políticas que van desde los recovecos sucesorios (con la primogenitura al frente)

15 Zúñiga Lacruz, 2015, vol. 1, p. 490, que cataloga al personaje en la categoría de célibes esquivas (vol. 2, p. 538). 
hasta las características del buen gobernante, que estaban a la orden del día en las discusiones coetáneas ${ }^{16}$.

\section{ENTRE REYES Y CABALLEROS}

Con las comedias caballerescas se cambia ligeramente de tercio, pues el juego de tronos posee un acento mayor en el conflicto de poder y la violencia. Así, en Argenis y Poliarco el conflicto ya no gira en torno a la sucesión sino a la lucha por la corona de Sicilia, centro de una red de enredos sin pausa: a más de la rebelión del privado Lidógenes contra el rey Meleandro, reaparecen los amores secretos del monarca con la reina Hianisbe de Mauritania, casada con Túbal de Persia, y la intervención de Poliarco, delfin de Francia, que ama en secreto a Argenis sin descubrir su identidad por la enemistad entre sus reinos (vv. 2562-2573 y 2850-2857) y hasta vive un tiempo exiliado en África. En medio de esta madeja se relata un intento de asesinato al rey con una embajada fingida (vv. 2349-2352), que vale como caso único de ataque a un monarca legítimo - que no tirano- en este grupo de comedias.

En El castillo de Lindabridis se retoma el problema sucesorio con la variante de la elección del candidato más perfecto, que se ve truncada nuevamente por la muerte del rey Brutamonte de Tartaria. Dice la princesa Lindabridis:

$$
\begin{aligned}
& \text { Es de mi patria heredada } \\
& \text { costumbre, que no apellide } \\
& \text { el pueblo príncipe augusto, } \\
& \text { ni le adore, ni se humille } \\
& \text { al hijo mayor del rey; } \\
& \text { que solo hereda y preside } \\
& \text { el que él en su testamento } \\
& \text { a la hora del morirse } \\
& \text { deja en sus hijos nombrado; } \\
& \text { que así el imperio consigue } \\
& \text { altos reyes, porque todos, } \\
& \text { por llegar a preferirse }
\end{aligned}
$$

${ }^{16}$ Para la primera idea, ver Soons, 1989, pp. 639-640, que aprecia «una confusión radical entre la Alemania de otros tiempos y un mundo ficticio francés», que se tendría que confrontar con las crónicas y relaciones de sucesos de su tiempo. Acerca de la pseudo-historicidad de algunas comedias calderonianas, ver Hildner, 2008. 


$$
\begin{aligned}
& \text { a sus hermanos, se crían } \\
& \text { magnánimos y sutiles, } \\
& \text { doctos en ciencias y en armas: } \\
& \text { sin que ley tan sola olvide } \\
& \text { las hembras, pues no lo es } \\
& \text { que el ser mujeres nos quite } \\
& \text { la acción de reinar. (vv. 177-195) }
\end{aligned}
$$

Para frenar las "guerras civiles» (v. 224) desatadas entre los partidarios de Lindabridis y Meridián está la justa, que enfrenta a Febo de Francia, Rosicler de Tracia, Floriseo de Persia y Claridiano de Tinacria (máscara de Claridiana) por el amor de la princesa y el cetro de Tartaria, que finalmente se salda con una carambola que establece un nuevo orden en tres reinos: Claridiana y Febo al frente de Francia, Rosicler y Lindabridis en Tinacria y Meridián en solitario como rey de Tartaria.

Auristela y Lisidante principia con la muerte de Polidoro, rey de Gracia, en un desgraciado accidente con Lisidante, que da pie a un vacío que corresponde a Auristela o Clariana, puesto que un peligroso parto - y una cierta despreocupación general- hizo que sean "tan iguales que Dios solo / es el que sabe a cuál toca / ocupar el regio solio» (vv. 152-154), que se solventa de una manera harto insólita: frente a las voces que reclaman los derechos de una $\mathrm{u}$ otra, ellas defienden el gobierno conjunto, porque son «amigas y hermanas $[\ldots], /$ tanto que reinar las dos / será reinar la una» (vv. 210-212). La solución cordial no satisface a casi nadie por los riesgos que entraña, y con toda razón, ya que los deseos amorosos (por Arsidas y Lisidante) introducen la discordia entre las hermanas y el matrimonio lleva consigo el peligro tanto de escisión del reino (vv. 212-214) como de ruptura de la concordia («será obedecer dos dueños», v. 223), que se agrava con la intervención de otros poderosos (Cintia de Chipre y Aurora de Epiro) hasta que el duelo final permite un casamiento múltiple ("cuadralbas bodas», v. 4260) que las gemelas gobiernen al alimón: «quedáis reinas tú y tu hermana, / sin que el reino se divida» (vv. 4231-4232).

Por fin, se echa el telón con Hado y divisa de Leonido y Marfisa, comedia en la que se cruzan las peripecias con las anagnórisis y se riza el rizo de la pelea por el poder: «faltando varón» (p. 115), por la corona de Trinacria compiten las hermanas Arminda y Mitilene en una guerra civil desencadenada tras descartar el «litigio / judicial» y el «último juicio del tribunal de las armas» (p. 116), en la que colaboran los príncipes 
Adolfo de Suecia y Florante de Rusia, y que se salda con el arbitrio final del rey Casimiro de Chipre, que solventa tanto los problemas de identidad de los personajes como el pleito por el reino.Y es que al final resulta que Leonido de Tiro, lansgrave de Persia (de Asia o Grecia, según otros lugares del texto) que había crecido al amparo del gran duque de Toscana y había tenido que esquivar mil y un peligros a lo largo de la acción, es el legítimo heredero de Tinacria, logrando de una vez el poder y el amor de Arminda, con lo que la comedia acaba con un happy end de manual en el que todos ganan. $\mathrm{O}$ casi, porque resta un hilo suelto: la muerte traicionera de Polidoro a manos de Florante queda secreta y sin castigo («Pues mi delito en silencio / queda, venturoso he sido», p. 231), lo que constituye un ejemplo sorprendente en Calderón.

\section{CODA FINAL}

En resumidas cuentas, este grupo de comedias palatinas y caballerescas parecen el esquema ideal para la representación de las disputas por el poder, uno de los nudos gordianos de la política de todos los tiempos. En este juego de tronos Calderón combina siempre los enredos amorosos con los tejemanejes políticos según unas modulaciones que abarcan el cambio de opinión en las preferencias de las damas (La selva confusa, Mujer, llora y vencerás) y la competición armada por un ducado o un reino.

De las comedias palatinas a los dramas caballerescos crece la fuerza de la violencia y la complejidad de los enredos, que abrazan con más frecuencia casos de identidad perdida y conflictos con otras naciones, mientras las peleas suelen quedar en casa en las primeras, con la notable excepción de Afectos de odio y amor y La selva confusa. Igualmente, la violencia gana enteros en las historias de caballeros y reinos, al tiempo que en unas y otras importa el retrato positivo de las figuras femeninas, personajes de armas tomar que defienden sus derechos contra tirios y troyanos con la ley sálica de por medio, que en algún caso (la lucha entre hermanas de Lances de amor y fortuna) desaparece por completo. Estos y otros elementos esencialmente serios que se arremolinan en torno a los conflictos de poder valen para — con más veras que burlas - armar el juego de la comedia en Calderón. 


\section{BiBLIOGRAFÍA}

Arellano, Ignacio, «Metodología y recepción: lecturas trágicas de comedias cómicas», en Convención y recepción: estudios sobre el teatro del Siglo de Oro, Madrid, Gredos, 1999, pp. 13-36. [Antes en: Criticón, 1990, pp. 7-21.]

Arellano, Ignacio, Los rostros del poder:ingenio y espectáculo, Sevilla, Renacimiento, 2011.

Calderón de la Barca, Pedro, Afectos de odio y amor, en Tercera parte de comedias, ed. Don W. Cruickshank, Madrid, Biblioteca Castro, 2007, pp. 467-589.

Calderón de la Barca, Pedro, Argenis y Poliarco, ed. Alicia Vara López, Madrid / Frankfurt, Iberoamericana / Vervuert, 2015.

Calderón de la Barca, Pedro, Auristela y Lisidante, ed. Rocío Arana Caballero, Madrid / Frankfurt, Iberoamericana / Vervuert, 2012.

Calderón de la Barca, Pedro, El castillo de Lindabridis, ed.Victoria B. Torres, Pamplona, Eunsa, 1989.

Calderón de la Barca, Pedro, Hado y divisa de Leonido y Marfisa, en Verdadera quinta parte de comedias, ed. José M. ${ }^{a}$ Ruano de la Haza, Madrid, Biblioteca Castro, 2010, pp. 85-231.

Calderón de la Barca, Pedro, Lances de amor y fortuna, en Primera parte de comedias, ed. Luis Iglesias Feijoo, Madrid, Biblioteca Castro, 2006, pp. 663-755.

Calderón de la Barca, Pedro, La selva confusa, ed. Erik Coenen, Kassel, Reichenberger, 2011.

Calderón de la Barca, Pedro, Mujer, llora y vencerás, en Verdadera quinta parte de comedias, ed. José M. ${ }^{a}$ Ruano de la Haza, Madrid, Biblioteca Castro, 2010, pp. 337-445.

Calderón de la Barca, Pedro, Para vencer amor, querer vencerle, en Sexta parte de comedias, ed. José M. ${ }^{2}$ Viña Liste, Madrid, Biblioteca Castro, 2010, pp. 12131313.

Coenen, Erik, «Calderón, educador de príncipes», en Emocionar escribiendo: teatralidad y géneros literarios en la España áurea, ed. Lucia Gentilli y Renata Londero, Madrid / Frankfurt, Iberoamericana / Vervuert, 2011, pp. 147157.

Cruickshank, Don W., Calderón de la Barca: su carrera secular, trad. José Luis Gil Aristu, Madrid, Gredos, 2011. [Original: Don Pedro Calderón, Cambridge, Cambridge University, 2009.]

Dahlgren, Sharon G., «La semiótica de los gemelos en Calderón: Mujer, llora $y$ vencerás», Dispositio, 13, 33-35, 1988, pp. 179-195.

Hildner, David J., «Semi-historicidad y seudo-historicidad en el ciclo italiano de Calderón», Teatro de palabras, 2, 2008, pp. 1-12. Disponible en línea: <http://uqtr.ca/teatro/teapal/TeaPalNum02Rep/1DavidHildner.pdf> [12/09/2016]. 
Kantorowicz, Ernst H., Los dos cuerpos del rey: un estudio de teología política medieval, trad. S. Aikin Araluce y R. Blázquez Godoy, Madrid, Alianza, 1985. [Original: The King's Two Bodies: A Study in Mediaeval Political Theology, Princeton, Princeton University, 1957].

Rull, Enrique, «El camino de la mina, vehículo de emociones en Calderón», Revista de Literatura, 64, 128, 2002, pp. 385-411.

Sáez, Adrián J., "Las caras del poder en la comedia religiosa de Calderón", en El universo simbólico del poder en el Siglo de Oro, ed. Álvaro Baraibar y Mariela Insúa, New York, Instituto de Estudios Auriseculares, 2012a, pp. 267-282. Disponible en línea: <http://dadun.unav.edu/bitstream /10171/23093/4/18_Saez.pdf> [12/09/2016].

SÁEz, Adrián J., "Embajadas y guerras: algunos paradigmas compositivos en el auto sacramental de Calderón», Anuario Calderoniano, 5, 2012b, pp. 215-231.

SÁEz, Adrián J., “¿Simular o disimular?: una nota a El mayor encanto, amor de Calderón", Creneida: Anuario de Literaturas Hispánicas, 2, 2014, pp. 430436. Disponible en línea: < http://www.creneida.com/revista/creneida-2-2014/simular-o-disimular-una-nota-a-el-mayor-encanto-amor-decalder\%C3\%B3n-adri\%C3\%A1n-j-s\%C3\%A1ez/> [12/09/2016].

SÁEz, Adrián J., «De la privanza en Calderón: Los cabellos de Absalón y La hija del aire», Bulletin of Spanish Studies, 92, 2, 2015, pp. 167-177.

SÁEz, Adrián J., «El drama de la diplomacia: embajadas y otras misiones en Calderón», en prensa.

Soons, Alan C., "Alemanes de leyenda en Mujer, llora y vencerás de Calderón», en Actas del IX Congreso de la Asociación Internacional de Hispanistas, ed. Sebastian Neumeister, Madrid / Frankfurt, Iberoamericana / Vervuert, 1989, vol. 1, pp. 635-644.

Strosetzki, Christoph, «La filosofía política, el tacitismo español y Calderón» en Calderón y el pensamiento ideológico y cultural de su época. XIV Coloquio Anglogermano sobre Calderón, coord. Manfred Tietz y Gero Arnscheidt, Stuttgart, Franz Steiner, 2008, pp. 533-549.

Vega García-Luengos, Germán, «Imitar, emular, renovar en la comedia nueva: Cómo se comunican dos estrellas contrarias, reescritura "calderoniana" de Las almenas de Toro", Anuario Lope de Vega, 11, 2005, pp. 243-264.

VITSE, Marc, Éléments pour une théorie du théâtre espagnol du XVII siècle, Toulouse, Presses Universitaires du Mirail, 19902. ${ }^{\text {a }}$ ed.

Weller, Thomas, «Poder político y poder simbólico: el ceremonial diplomático y los límites del poder durante el Siglo de Oro español», en Autoridad y poder en el Siglo de Oro, ed. Ignacio Arellano, Christoph Strosetzki y Edwin Williamson, Madrid / Frankfurt, Iberoamericana /Vervuert, 2009, pp. 213239.

Zúñiga LaCruz, Ana, Mujer y poder en el teatro español del Siglo de Oro: la figura de la reina, Kassel, Reichenberger, 2015, 2 vols. 
Zugasti, Miguel, "Comedia palatina cómica y comedia palatina seria en el Siglo de Oro", en El sustento de los discretos: la dramaturgia áulica de Tirso de Molina. Actas del Congreso Internacional organizado por el GRISO, coord. Eva Galar y Blanca Oteiza, Instituto de Estudios Tirsianos, Pamplona / Madrid, 2003, pp. pp. 159-185. 